\title{
Can we educate out of racism?
}

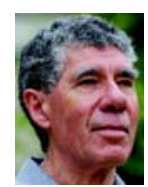

\section{Dennis McDermott argues that educating doctors about the health consequences of everyday racism towards Indigenous Australians challenges all involved}

genuine engagement with Indigenous health issues challenges medical students and doctors alike. When participants in medical education analyse racism as a social determinant of health, the challenge deepens. The experience can range from disquieting to profoundly disturbing. For educators, the experience can be stressful, even daunting.

Analysing racism in medical education is not an optional extra, given that there is a nationally mandated objective of training doctors to work effectively with Aboriginal and Torres Strait Islander Australians. Doctors need a grounding in the health consequences of racism and an appreciation of the widespread, systemic discrimination that exists. This includes understanding how the resultant inequitable access to services, patient non-compliance, "taking own leave" from hospital and ineffective health promotion compromise Indigenous health outcomes.

The literature provides solid evidence that racism is a noteworthy determinant and driver of inequities in health. ${ }^{1}$ Several meta-analyses have shown many effects on mental health, ${ }^{2}$ and over 100 studies from the past 15 years address the increasingly recognised physiological consequences for the person targeted with racism, including cortisol dysregulation. ${ }^{3}$ Racism is not only an everyday occurrence for many Indigenous Australians, but also one that gets under the skin, and "makes us sick". 4

In the nation at large, though, racism bypasses consciousness. Although living in the same country, many non-Indigenous Australians would have difficulty recognising the world of corrosive attitudes that many Indigenous Australians report. If you're neither target, nor witness, you miss racist events. The more invisible the racism, the harder it is to comprehend its pervasiveness and potency as a social determinant of health. The evidence may be "in", but relying on the power of evidence alone may not be enough. The Australian self-image of a tolerant, multicultural success story leaves little room for a counter-discourse of a more complex reality, grounded in a historical, de facto apartheid, and there is a resurgence of bipartisan paternalism. This is evident in the reimposition of the Northern Territory "emergency response" for a further 10 years, under the Orwellian "Stronger Futures" label.

Whether the educational setting is a primary medical degree or further professional development, participants report bringing low levels of understanding of Indigenous issues with them. A new paradigm of learning must emerge. 35: 888-901. Unit, 2009.
Without a critical social and political lens, it may be difficult to recognise that racial denigration serving political or corporate ends may be dressed up as racial "fact". It may not be possible for people to know whether a statement is supported by more than anecdotal report, such as the comments of someone shortlisted as a National Living Treasure, Andrew "Twiggy" Forrest, on Pilbara Aboriginal people:

[When] little girls come up to you ... and offer themselves ... for the cost of a cigarette, then you know you've come to the end of the line. Social breakdown is complete. Now I'm not going to encourage with our cash that kind of behaviour...5

In the health professions, there are elements of a false dichotomy separating clinical competence from self-reflective practice. There is great diversity in the capacity of students for critical reflection, even in graduate-entry medicine. One medical student, who already had a $\mathrm{PhD}$, commented that he and his peers were concrete thinkers, and could we simply offer them the "solutions"? An academic colleague, revising pathways for upskilling from enrolled nurse to registered nurse qualifications, noted that nursing needed more "task people" and fewer "thinkers". Becoming a thinking, culturally safe practitioner is also the prerequisite for emerging as a clinically safe one. The pedagogical strategy of taking students on a journey of discovery, the basis of our approach at Flinders University, is undermined when uncertainty, along with a critical stance, is resisted.

Dennis R McDermott $\mathrm{BEC}, \mathrm{BA}($ Hons) (Psych), MA,
Director

Poche Centre for Indigenous Health and Well-Being, Faculty of Health Sciences, Flinders University, Adelaide, SA.

dennis.mcdermott@ flinders.edu.au

doi: 10.5694/mjal2.10936 disassembling existing planks of belief: a transformative unlearning. ${ }^{6}$ Good cultural-safety education generates disquiet, but makes the uncomfortable comfortable enough, through sensitive classroom facilitation in a mutually respectful environment. When an Indigenous health curriculum includes analyses of the health consequences of racism — as it needs to - it struggles against nonrecognition of racist acts and systemic discrimination. The challenge, then, is twofold: to make the invisible visible, and to facilitate a "manageable" disquiet.

Acknowledgements: Dianne Gabb, David Sjoberg, Courtney Ryder and Pauline Guerin have taught Indigenous health with me, codeveloped curriculum and identified educational barriers and fresh pedagogical strategies.

Competing interests: No relevant disclosures.

Provenance: Commissioned; not externally peer reviewed.

1 Harris R, Tobias M, Jeffreys M, et al. Effects of self-reported racial discrimination and deprivation on Mâori health and inequalities in New Zealand: cross-sectional study. Lancet 2006; 367: 2005-2009.

2 Paradies Y. A systematic review of empirical research on self-reported racism and health. Int J Epidemiol 2006

3 Drexler M. How racism hurts-literally. Boston Globe 2007; 15 Jul: El.

4 Gallaher G, Ziersch A, Baum F, et al. In our own backyard: urban health inequities and Aboriginal experiences of neighbourhood life, social capital and racism. Adelaide: South Australian Community Health Research

5 Cronau P, Michelmore K. Iron and dust. ABC TV Four Corners 2011; 18 Jul. http://www.abc.net.au/4corners/ content/2011/s3272125.htm (accessed Jun 2012).

6 Ryder C, Yarnold D, Prideaux D. Learning and unlearning: is communication with minority patients about self or others? Med Teach 2011; 33: 781-782. 